\title{
Selective Retreat Scenarios for the Po River Delta
}

\author{
Roberto Di Giulio, Luca Emanueli, \\ Gianni Lobosco, Emanuele Piaia, Marco Stefani
}

\begin{abstract}
The increasing hydro-morphological and environmental degradation of lagoon systems is an issue shared by many Mediterranean contexts. A Selective Retreat Strategy could be a radical solution for these sites, in order to better manage the investments and maximize the efforts on some specific settings, deliberately omitting others. This approach comes from a research program developed by Sealine (Ferrara University) on the delta of the Po River. Such lagoon system is highly unstable, vulnerable to intense dynamics (coastal erosion, subsidence, saltwater intrusion, etc.) affecting both its ecological value and the human activities taking place around it (agriculture, fishing, aquaculture, tourism). The infrastructural effort to freeze its evolution is no longer maintainable and increasingly less efficient, given the site dimension and complexity. Besides these remarks, such proposal is encouraged by specific boundary conditions like the low productivity of farming areas and the land ownership arrangements based on few big properties. Therefore, it is possible to envisage a progressive site reorganization according to its historical character of evolving landscape shaped, over the centuries, by the alternation of natural phenomena and human interventions.
\end{abstract}

Keywords: evolving landscapes, hyper-natural landscapes, scenariobased approach, Selective Retreat Strategy

Delta regions have always been attractive sites for human settlements, due to their fertility, abundant water supply, proximity to fluvial and maritime waterways, etc. Deltas are among the most densely populated areas on 


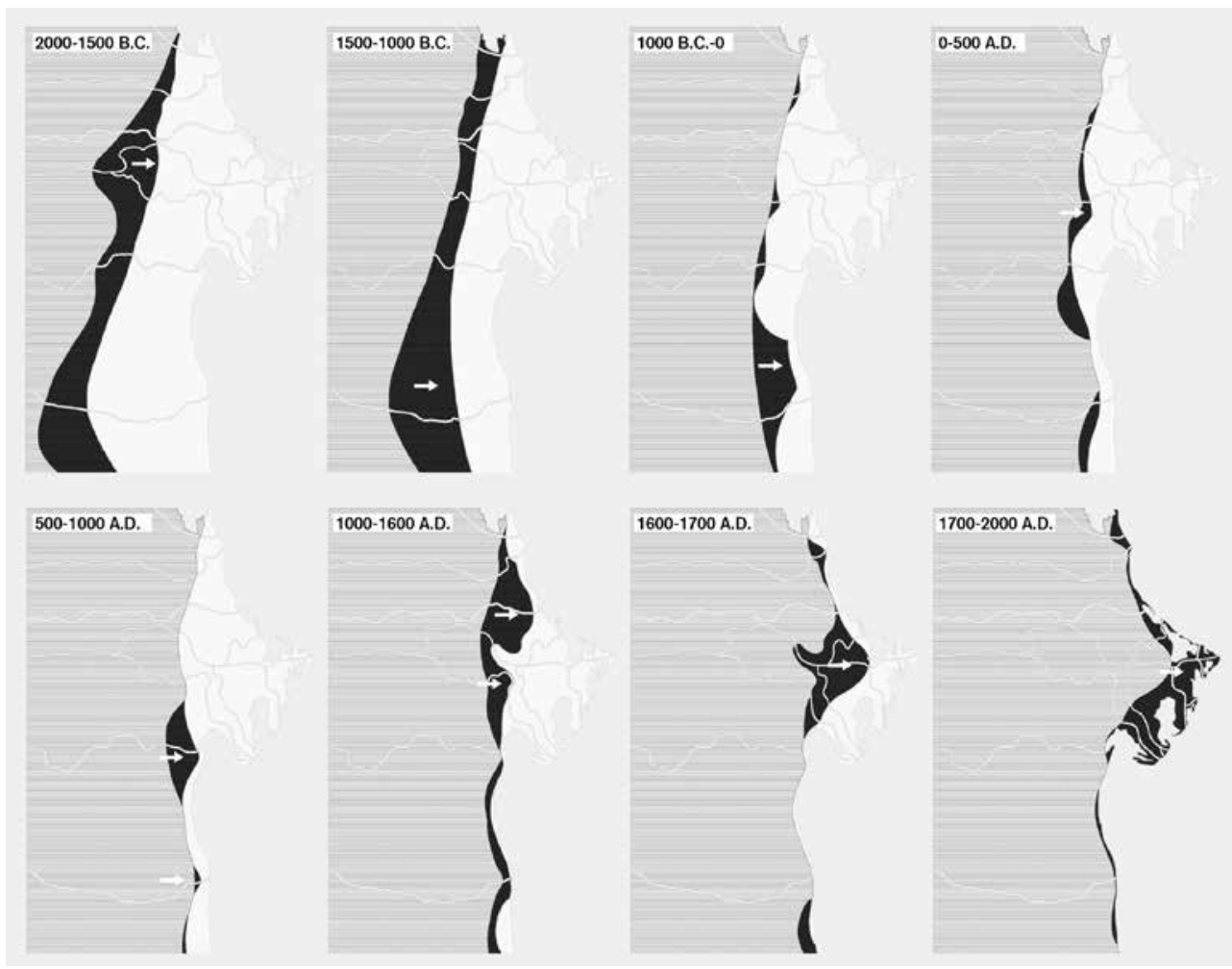

Figure 1. Age of deposition of the different sediment belts now forming the Po Delta coastal plain, between the Venice Lagoon and Ravenna (Italy).

the planet. According to the International Geosphere-Biosphere Program (Syvitski, 2008), they account for more than 500 million inhabitants, almost $7 \%$ of the world population. Until the last century, life on deltas was largely subject to natural uncertainty and large floods were ordinary phenomena to deal with. Through the last two centuries, the fluvial dynamics has been however largely altered by human intervention, such as land reclamation and river embankment in most deltas. A raising conflict is taking place in many delta areas: the human's will to exploit natural resources within a stable framework clashes against the dynamic processes constantly reshaping the delta environment. In the last decades, in the Mediterranean region, deltas have undergone an increasing environmental degradation. A rigid and unchangeable framework created by massive human interventions was superimposed onto natural environments with a very large mobility. Sharp reduction in the sediment input, large fresh water consumption, subsidence accelerated by human interventions, delta water salinization, water eutrophication, global climate change and eustatic change combine and make the environmental management of delta area increasingly difficult. Basic morphological elements such as coastal sand spits tend to wear out, failing in their task to soften the wave impact. Drastic reductions in flora and fauna population have also often been witnessed. Without human intervention, many delta areas would be rapidly submerged by fast marine transgression (Overeem and Brakenridge, 2009). 


\section{THE PO DELTA SYSTEM AND ITS MANAGEMENT STRATEGY}

The Po River Delta in Italy is an important example of how such complex issues have been intertwined over time with urban, social and economic developments, which have characterised the evolution of the so-called "Megalopoli Padana" (or "Po Valley Megalopolis"). This geographical notion (Gottmann, 1978) has been used by Eugenio Turri in 2000 to describe the peculiar urban growth through the entire alluvial valley of the Po River, from Turin to the Adriatic Sea. In fact, according to Turri, the whole territory included between the river and the Via Emilia road can be described as a continuum, where agricultural fields have today become interstitial areas incorporated within dense urbanizations across the plain. A system that has developed following partial and heterogeneous interests at the local scale, rather than an overall design, resulting in a "vast machine" exploiting a territory of extraordinary resources, able to offer an amazing variety of industrial and agricultural products, and profoundly shaped by man to the needs of anthropization.

In this framework, the Po Delta and its present fragility represent the outcome and the clear evidence of the major changes that have affected the whole fluvial system during the last century to say the least.

Anyway, such condition of instability is not new. The current layout of the Po Delta of Northern Italy is the result of continuous anthropic actions started in 1604 with the so-called "Porto Viro cut," which enabled the main distributary channel to flow southward, in order to protect the Venetian Lagoon from silting (Fig. 1). During the centuries, similar works have been constantly carried out, in the double effort to defend settlements and reclaiming large areas from the sea. Nowadays, the Po Delta covers an area of 18.000 ha [44,479 acres], $8.150[20,139]$ of which are occupied by lagoons, 8.600 $[21,251]$ by fishing diked lagoons, over $1.250[3,089]$ by wetlands.

The present delta morphology is an over-engineered system in which any kind of interaction is hardened and strictly mediated and controlled (Fig. 2). Against this logic, the Retreat Strategy aims to provide a different approach to environmental management and a long-term vision driven by pragmatic evaluations. Through the last few years, a certain ambiguity has grown in the landscape planning of coastal and deltaic contexts. Scientific studies and planning procedures on deltas have mainly focused on environmental remediation, ecological restoration and the so-called "re-naturalisation" processes. According to this approach, the landscape should somehow be brought back to a previous "natural" state, whose characteristics however actually belong to a very specific evolutionary phase. Fast evolving contexts such as deltas have often been considered and managed as if their dynamic attitudes were something to be fixed or eliminated rather than being included into planning policies. The European and national regulatory framework itself, following the same logic, identifies protected areas and high environmental interest zones (known as "Natura 2000" sites, under the 92/43/CEE "Habitat" Directive) as permanent in time and space. 


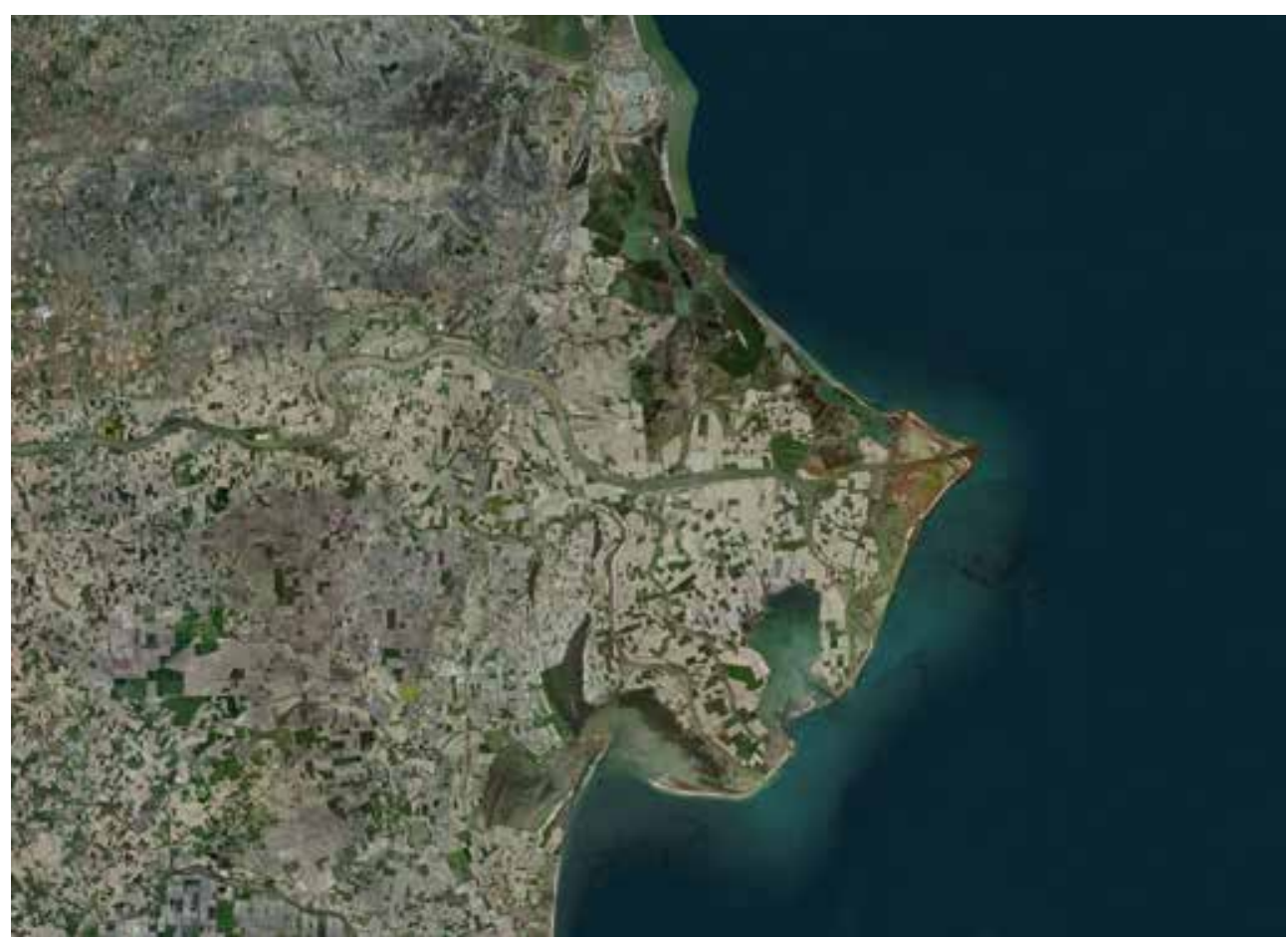

Figure 2. Satellite view of the present day Po Delta configuration.

This is in sharp contrast with the high natural mobility of the deltaic systems. Littoral zones, dune systems and wetlands need to be identified and protected through more flexible instruments, assuming their mobility and the chance to be relocated elsewhere. In a near future, the delta planning authorities will not be able to manage environmental changes anymore without being allowed to take more radical and faster decisions. Therefore, environmental protection instruments, such as the ones mentioned before, need to be updated and adapted to highly mobile context framework.

The comparison of different generations of aerial photos, taken since 1950, shows the ongoing process of the sea retaking its space on the delta's top plain, re-flooding broader and broader areas and affecting human activities, settlements and their safety (Fig. 3). At the same time, territorial policies are still mostly tied to the assumption that there is an ideal delta environment and that it must be kept "frozen" at any cost. Several environmental emergencies have however been threatening the Po Delta fragile balance. The relative sea level rise (subsidence and eustatic change), by boosting the saltwater intrusion, already affects negatively most of the cultivations. A critical factor is the constant reduction of fluvial sediment supplies to the sea, mainly due to the extraction of raw materials all along the river course. From 1958 to 1981, the loss of sediments to the delta system has been estimated at 90-95 million $\mathrm{m}^{3}$ [117,716-124,225 cu.yd.] (Simeoni et al., 2007). Dramatic subsidence acceleration started in the '50s in the Po Delta, due to an intense methane baring water extraction. Between 1950 and 1980, the coastal Polesine area experienced a sensational subsidence (Tosini and Colombo, 2009) of up to 40 

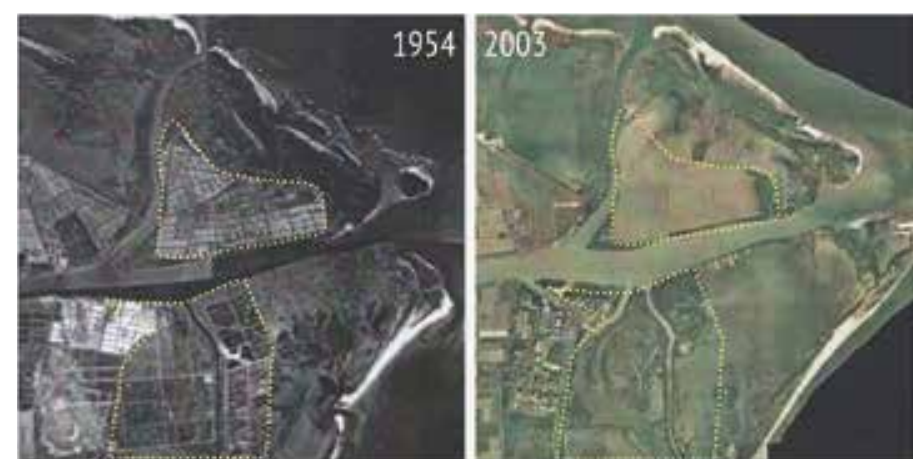

Pila Po river branch (1954 - 2003)
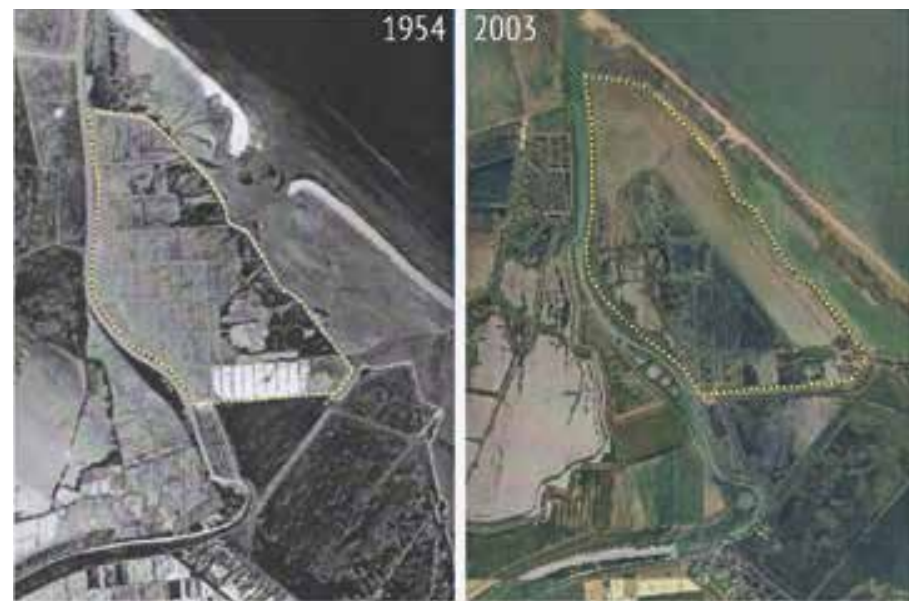

Maistra Po river branch (1954 - 2003)

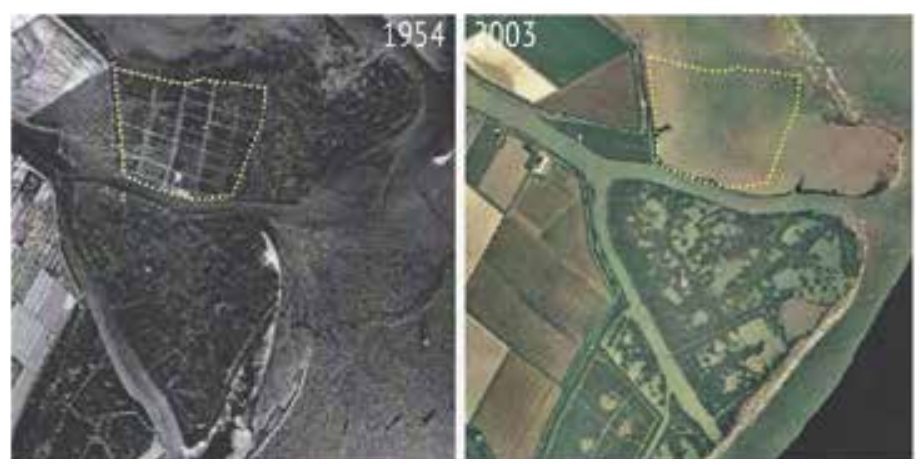

Gnocca Po river brach (1954 - 2003)
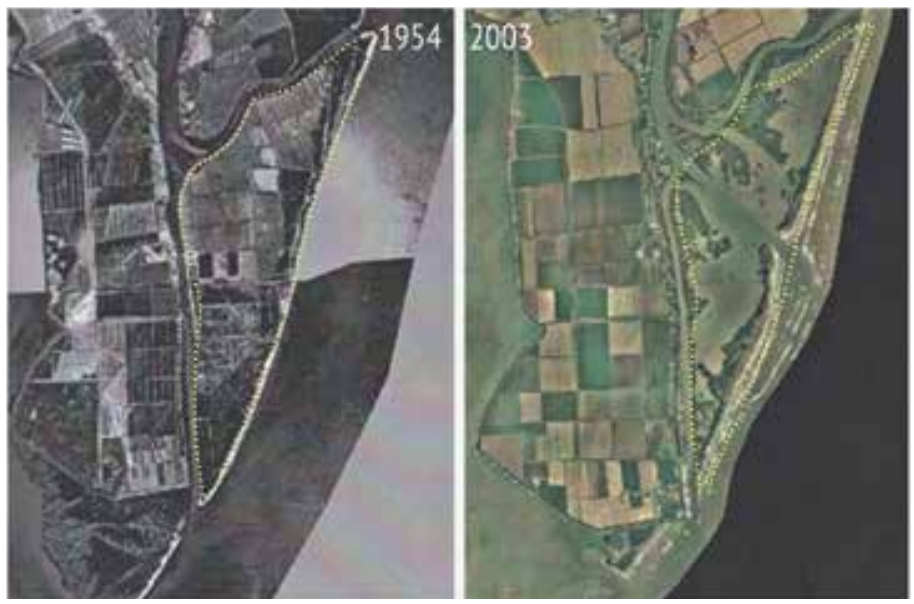

Talle Po river branch (1954 - 2003)

Figure 3. Examples of the widespread erosive retreat affecting the Po Delta coastline.

and $60 \mathrm{~mm}$ [1.57 and $2.36 \mathrm{in}$.] per year. Extraction was totally forbidden in the '70s, but only during the early ' 90 s, the subsidence value started to go back to more natural values of approximately $2-4 \mathrm{~mm}$ [0.08-0.16 in.] per year (Bondesan et al., 1995).

More than four-fifths of the area is already well under the average sea level, even below $-4,5 \mathrm{~m}$ [-14.76 ft.] (Fig. 4). The altimetry condition is worsened by external factors, such as the global eustatic sea level rise predictions that are to be about 1-1,5 $\mathrm{m}$ [3.28-4.92 ft.] by the year 2100 , according to the Intergovernmental Panel on Climate Change.

\section{EXAMPLES OF SELECTIVE RETREAT}

The combination of fast subsidence, eustatic rise, climate change, and sediment input starvation, water pollution, and deterioration of the infrastructures will soon make maintaining the current delta configuration very difficult. Even more rigid protection works will be required, causing a further stiffening of the entire hydro-morphological lagoon system.

Persisting on this course of action implies building in the future even higher 
embankments to protect sunken and unprofitable areas.

The futile attempt to crystallize and fully control such a changeable system is a losing approach, as events have already shown. In the long-term, such efforts will not be sustainable, neither environmentally nor economically. Innovative strategies grounded on the intrinsic dynamism of the Po Delta system are therefore strongly needed. It is clear that the present rigid environmental framework will soon become untenable and a retreat of human activity from the artificially reclaimed areas, well below sea level, will become unavoidable. A project of Selective Retreat Strategy implies policies aiming at abandoning to the marine transgression selected delta areas and at re-organizing the whole delta dynamic landscape.

Various desertion plans have already been carried out in several regions of the world, yet trying to give an answer to different issues, needs, and objectives. These examples are mostly the result of powerful economic interests, but they are also useful to envisage the social and economic impacts of transferring people, activities and urban services from one place to another.

It is not so uncommon to relocate entire villages and communities, in order to allow the construction of highways and dams (Égré and Senécal, 2003). This is the case of a southern Australian town that has been moved for about $8 \mathrm{~km}$ [4.97 mi.] in the '50s to make way for the expansion of the massive Lake Hume Dam. More recently, in 2008, the Hubei Province of China witnessed the relocation of 1,24 million Sandouping residents,

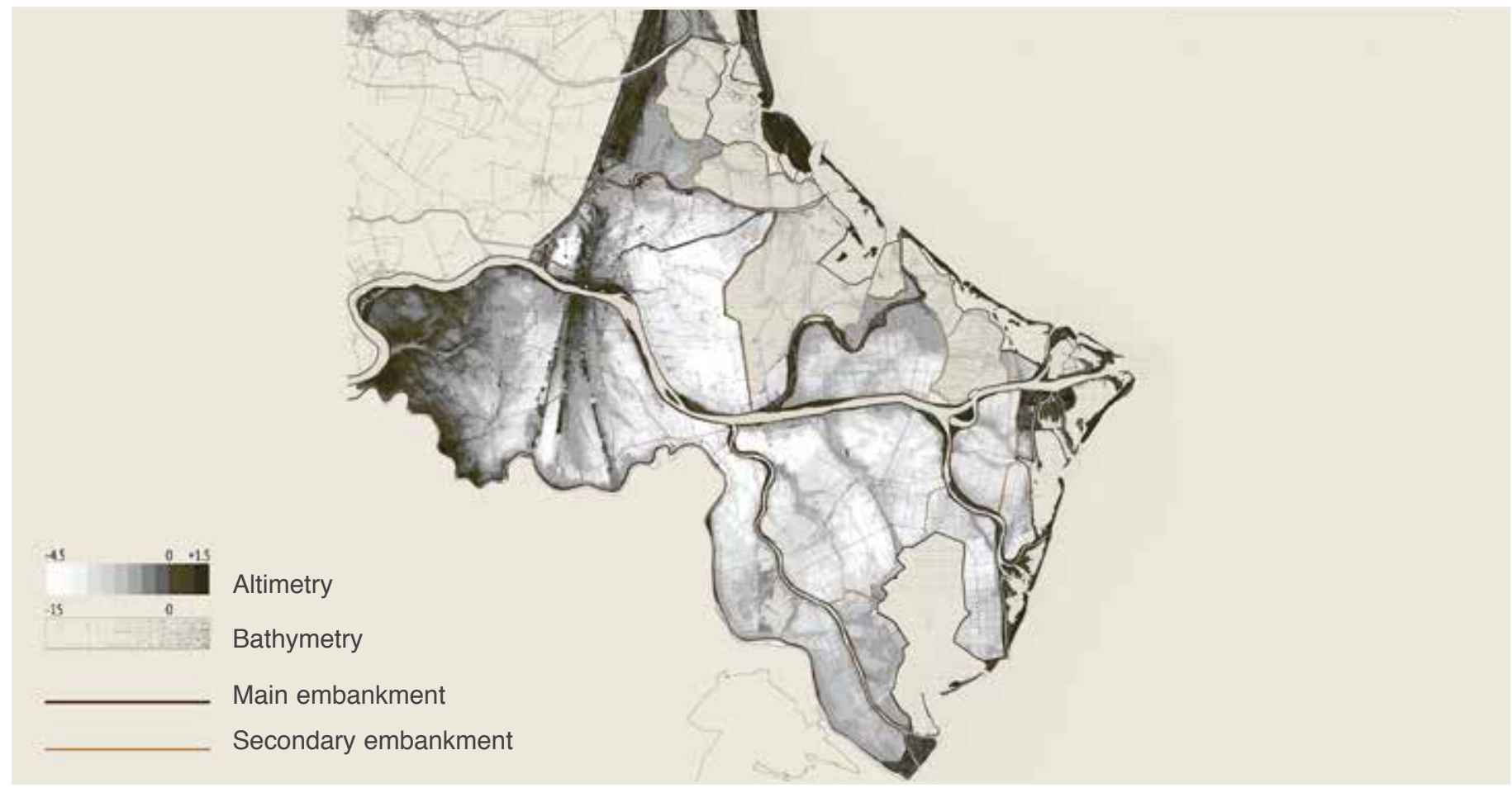

Figure 4. Po Delta plain elevation model. Note that the vast majority of the area is presently well below sea level and is artificially kept dry by large land reclamation works. 
due to the construction of the Three Gorges Dam, a major infrastructure crosscutting the Yangtze River.

In others cases, a crisis resulting from aggressive mining close to urban areas forced the relocations of entire towns (Speller, Lyons, and TwiggerRoss, 2002). For instance, in the late 1910s, the Minnesota town of Hibbing was moved about $3 \mathrm{~km}$ [2 mi.] southward because of unstable ground caused by the town burgeoning iron mine. A similar destiny is now affecting the northernmost town in Sweden, Kiruna, which is currently caving in of the over-mining in the large Precambrian iron deposit. Officials are now tasked with moving the town about $4 \mathrm{~km}$ [2.48 mi.] eastward, in order to enlarge the mining site, keep the inhabitants safe, and develop an improved modern version of the city. Institutions, stakeholders and citizens have been engaging during this process in several common initiatives, with the overall objective of building a roadmap for the village transition; such roadmap is the outcome of several workshops aimed at informing the urban and infrastructural planning (Leonhardt, 2015) according to different scenarios. Even though the adopted methods are not exempt from criticisms, and the whole debate - as pinpointed by the Bo Nilsson's article (Nilsson, 2010) - has been affected by the ideological bias that characterizes various opinions in relation to relocation plans, the Kiruna case-study shows how democratic processes in the context of urban and territorial transformations could be managed and adopted to inspire a shared vision of the future.

The proposed Selective Desertion Strategy for the Po Delta aims at integrating such external forces into a long-term sustainable scenario of growth for the deltaic territories. Such hypothesis explores a retreat scenario, choosing certain areas to selectively flood or further protect, in order to develop new landscapes and new socio-economic opportunities. As evidenced by Ivan D. Correa and Juan Luis Gonzalez in 2000, such goals, in particular conditions, can be achieved only by taking radical choices rather than continuous technical compromises. In this perspective, a deeper awareness of Po Delta dynamics and more flexible planning rules are however needed. Nowadays, the whole delta territory is still highly fragmented in terms of planning and management authorities and this is a notable weakness not only for the proposed strategy implementation, but also for any kind of policy, even less radical, that will be applied in the future. For these reasons, a closer cooperation between public and private stakeholders, investors, enterprises and citizens is needed, as well as the rendering of more extreme scenarios could be useful to test the political will in tackling the issue, instead of reiterating the current attitude at postponing it.

\section{SELECTIVE RETREAT STRATEGY: THE PO DELTA CASE-STUDY}

The proposal of a Selective Retreat Strategy is rooted in an ongoing investigation aimed at the definition of new strategies to landscape, infrastructural and environmental evolution planning of coastal regions. 
The work is framed within a research programme on Hyper-Natural environments developed by the Sealine Research Centre of the Architecture Department, University of Ferrara. This multidisciplinary investigation involves academics, professionals, and university students into a shared research effort. In particular, thanks to the master thesis project of Lucia Ferrarini in 2015, the main hypothesis has been tested in smaller areas of the delta, in order to better understand and predict the landscape and infrastructural design implications.

The study started by analysing potential risk scenarios forecasted for the next decades. Extreme events such as sea storm surges, very high tides, and river floods were taken into account to highlight the large vulnerabilities and weakness spots of the Po Delta area. The Po Delta plain was subdivided into areas showing different levels of vulnerability, according to their propensity to river and sea flooding. An increasing "porosity degree" level has been assigned to these areas to subdivide the whole of the delta territory into areas with homogeneous "prospective retreat levels." The retreat strategy has been planned on this basis, aiming at both protecting and boosting the anthropic system developed in this fragile coastal area.

The analysis takes into account several key parameters:

- Areas below the sea level and coastal morphology vulnerability: given the severe subsidence affecting the Delta and the lack of sediment input, it is highly important to safeguard areas still above sea level. It is also important to describe the areas more susceptible to coastal erosion.

- Ecological habitats quality: it is possible to pinpoint the most valuable biotopes and foresee their preservation, based on several ecological studies (Pagnoni et al., 2009) measuring the biodiversity level in the delta.

- Settlements importance: the Po Delta, unlike other deltaic areas in the world, has a low and further decreasing population density: 93 inhabitants $/ \mathrm{km}^{2}$ [241 inhabitants/sq. mi.] (Tosi, 2013). Nevertheless, some villages have to be preserved due to their consistency and socio-economic value; due to the extremely recent geological origin and anthropic colonization, no historic centers are developed in the area.

- Existing economic assets: the most profitability areas, such as fishing lagoons, have to be preserved, as well as some industrial archaeology sites, dating to the nineteenth and twentieth century reclamation projects.

- Future development assets: some dismissed or underused areas could play, in the future, a central role for the development of tourism, transports and environmental functions.

Because of these analytical inputs, four successive retreat boundaries (i.e. desertion lines) have been planned (Fig. 5). These main steps will be leading to increasingly safer configurations of the delta system.

The planning has been traced to reach a progressive economic balance in the Po River Delta hydro-morphologic management: 
- Emerging lands are planned to decrease by $13 \%$ in the first phase, and $63 \%$, in the last one.

- The embankments length will decrease by $48 \%$, in the first phase, and $71 \%$, in the last one. The associated maintenance cost-saving will be effective from the beginning of the process.

- The delta distributary channels will shorten by $11 \%$ and $56 \%$ in the first and last phase, respectively. The channel shortening will increase the extremely low gradients, supporting an improved water flux.

- Lagoon area is expected to decrease by $74 \%$ in the first phase, then to increase through the flooding of new areas in the following project phases.

- The spontaneous wave erosion of the newly flooded coastal area will mobilize millions of cubic meters of sediment, now stored beneath reclaimed area, already below sea level. The sediment will be involved in the reshaping of the coastline, through the sea wave action, locally matched with artificial nourishment of sandy beaches.

- Inhabitant displacement would involve $2 \%$ of the delta region population at the first stage, up to $11 \%$ during the possible next retreat phases, involving a maximum of about 8.600 people. The ongoing decrease in population and the incomplete demographic turnover of the elder component will likely further reduce the number.
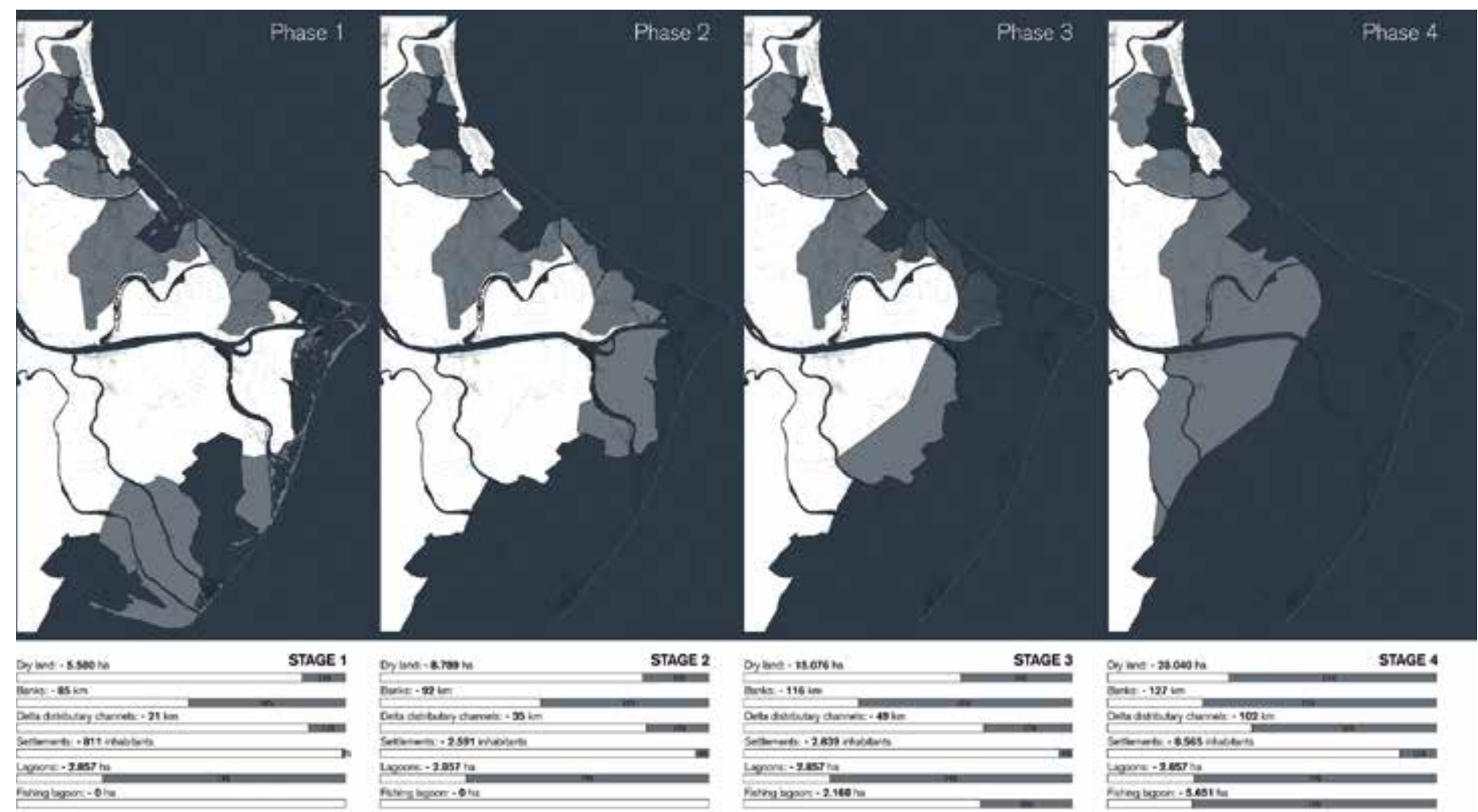

Figure 5. Planned stages of the anthropic retreat from the delta plain. 
In many cases, persisting in the protection of anthropic habitats would be economically unfavourable if compared to balancing their loss with the re-design of similar new sites elsewhere; in other cases, flooding an area would not be economically convenient. For instance, the huge dismissed thermoelectric plant in Porto Tolle, if flooded, would have to be completely remediated: an expense far greater than the investment required for keeping it dry and re-functionalizing it in a touristic perspective. At every stage of the retreat process, some sites are planned to be preserved from flooding, to form an artificial archipelago in front of the delta where several services and infrastructural facilities will be developed. Existing embankments or harbour works could be saved by becoming marinas or offshore cruise docks, with the aim of boosting the maritime accessibility to the area. Small isolated villages, such as Santa Giulia, San Rocco and Gorino, and other sites below sea level, could be networked and converted into diving parks. The whole archipelago system, besides its value as a focal element within the landscape, would probably act as a catalyst for the development of the delta tourism.

The project is now focusing on two main operative layers: the mobility infrastructure network and the wetlands system.

The infrastructural system needs to be reset before the starting of the regulated flooding process. Both existing and new infrastructures have to be connected to manage the population and economic activity resettlement. Several interventions are planned for resetting the territory according to the new scenarios, which would imply, for example, an increase in population in some areas and function losses in others. Roads will be designed following short and long-term previsions on rising relative sea level and catastrophic events. The roads already well under sea level and exposed to a high flooding risk will be abandoned. The new mobility network is planned through two types of roads corresponding to an increasing resiliency level. The first level consists of seasonal connections, conceived to be flooded under extreme overflow conditions, being just over the average sea level. They will shape the wetland landscape when the most advanced protections are dismantled. The second one is designed to be a long-lasting infrastructural level. This road system is patterned after existing main roads and embankments, set up to a safety elevation, and will ensure durable connections between dry lands. Road infrastructure will become the supporting framework of the retreat process, catalysing new functions and re-shaping the Po Delta's identity. Unlike today, the future Po Delta landscape will lay on a "branched" fruition system, rather than on the monotonous zoning of single-purpose areas (Fig. 6).

The present territorial layout, as developed from the 1951 Land Reform planning (Milan, Perini and Tognon, 2004) appears to be a large and uniform carpet, where rectangular fields and scattered houses monotonously recur. A few peculiar sites standing out from this uniform, flattened context struggle to become perceivable and attractive. 
The new mobility network is planned as a recognizable element within the landscape. Through the retreat process, the road infrastructure is designed to become a touristic element in itself, offering a unique way to visit the delta and its "water landscapes."

In order to control environmental and coastal dynamics, the project strategy relies on a new wetlands system that will evolve from the deliberate flooding of lower areas. Such operation will allow to contrast erosion phenomena both at the local - by dissipating the marine wave energy - and the territorial scale - by providing a great amount of additional material to the sediment transport along the littoral limiting the erosion of southern beaches. Wetlands also behave as expansion basins for river floods and their importance is associated with biodiversity conservation and improvement. All these qualities should be measured in the long term and according to an overall management of the different deltaic habitats.

Along the coastline, after removing a few portions of embankments, the sea will quickly retake large areas. In inner lands, artificial basins will keep fresh waters in order to prevent the salt-water wedge intrusion from reaching the inner delta plain and to improve the productivity of the remaining fields. In some cases, the flooding process will be achieved just by shutting down a few water pumps, so that the rainwater could fill the lower lands. It is almost impossible to predict exactly the final configuration of the coastline and the way the sandbars will migrate over the years. The persistence of a lagoon belt and inter-distributary bays between the coastal sand spits and the new delta borders is certainly the most likely scenario. Within the lagoon belt "buffer zone," many activities will be rearranged and enhanced such as the mussel culture, taking advantage from the increase of the shallow seabed areas. The controlled marine transgression process will also make available a large sediment stockpile that will be used for beach nourishments.

A similar approach could be carried out by tapping inland fluvial sediment by river-regulated floods into expansion basins. In this perspective, one of the most challenging zones is Porto Tolle, a 10.000 inhabitant settlement near the Po channel that would greatly benefit from the development of a sediment trapping overflow basin, protecting its eastern boundary. By lowering and strengthening the river south bank in a few points, overflow waters, which are the only ones rich in sediment, can be collected into the basin raising bottom. The silt up basin will eventually produce a valuable hydraulic protection against flooding, while generating new farmlands and building lots that could be assigned to farmers and inhabitants whose lands are vulnerable to flooding.

All these interventions consider the limit between land and water as a deep and dynamic space with soft transition borders and consistent resiliency sectors, devoted to mitigate extreme sea and river events. In such perspective, these areas are meant to work as biodiversity reserves that could host the local fauna relocation during the retreat process. 
WETLANDS AND VEGETATION
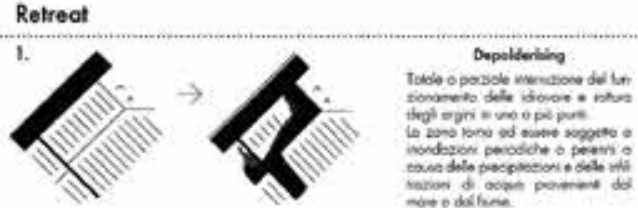

Controlled flooding
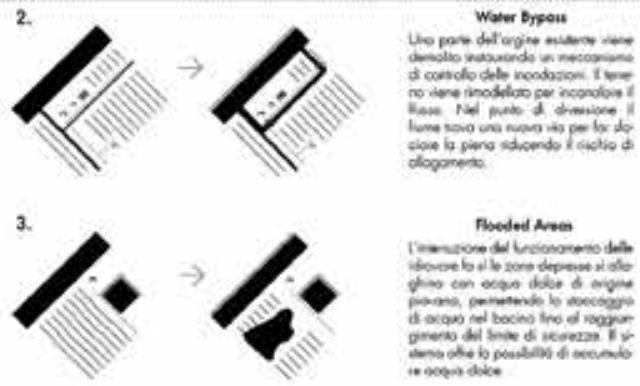

$<$

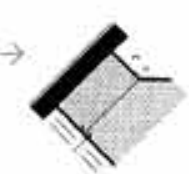

Stabilization
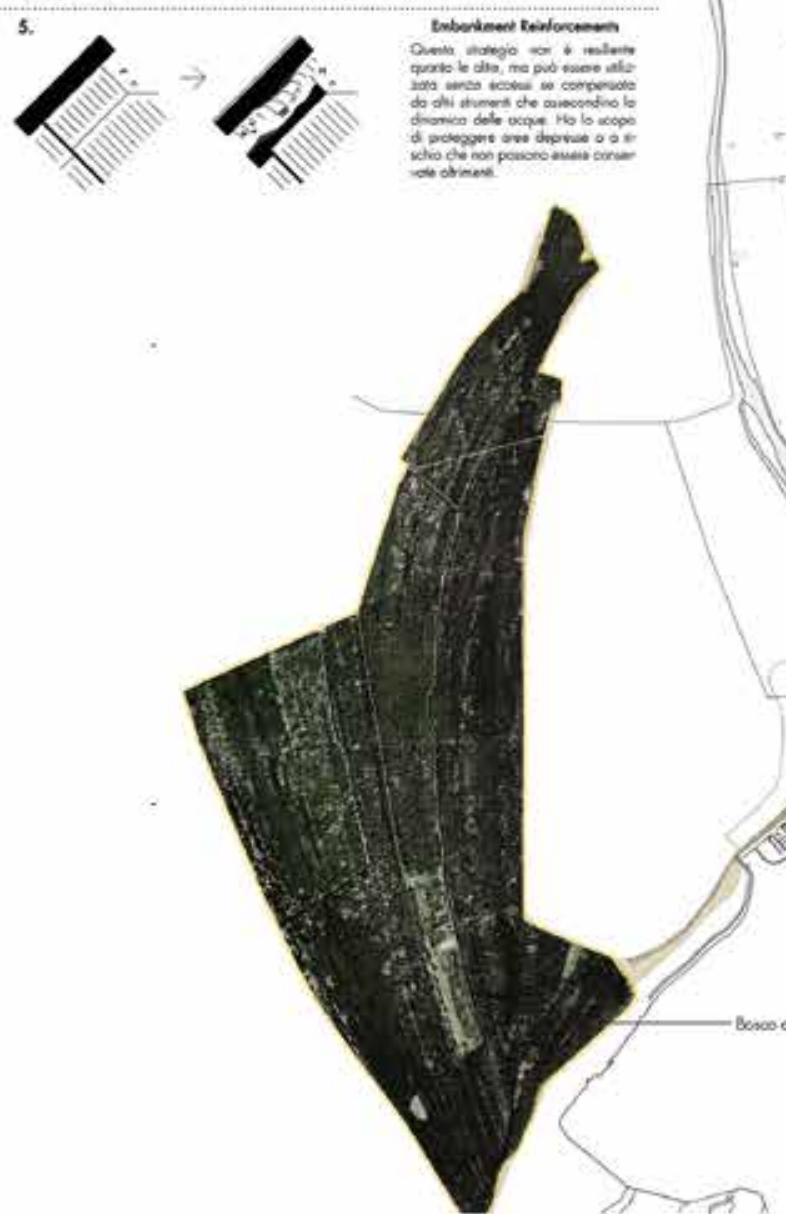

$$
-7
$$

Depolderising Process: 4 Steps

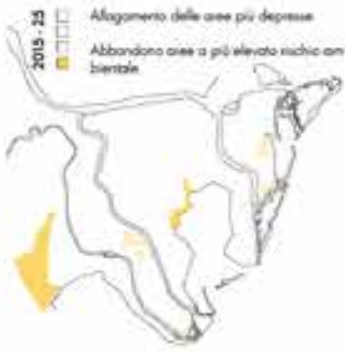

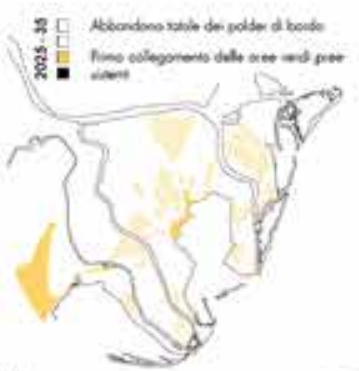
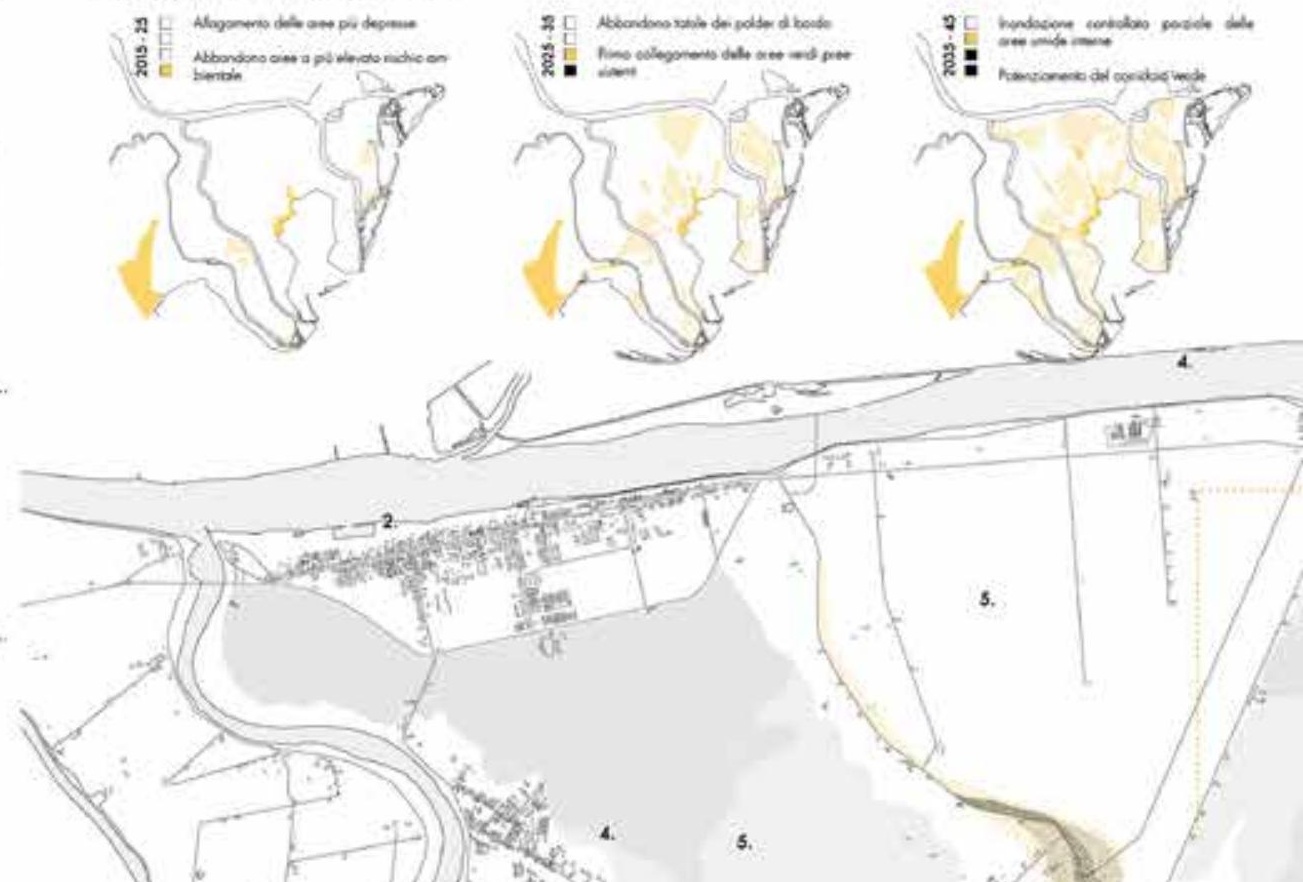


\section{Vegetation Study}
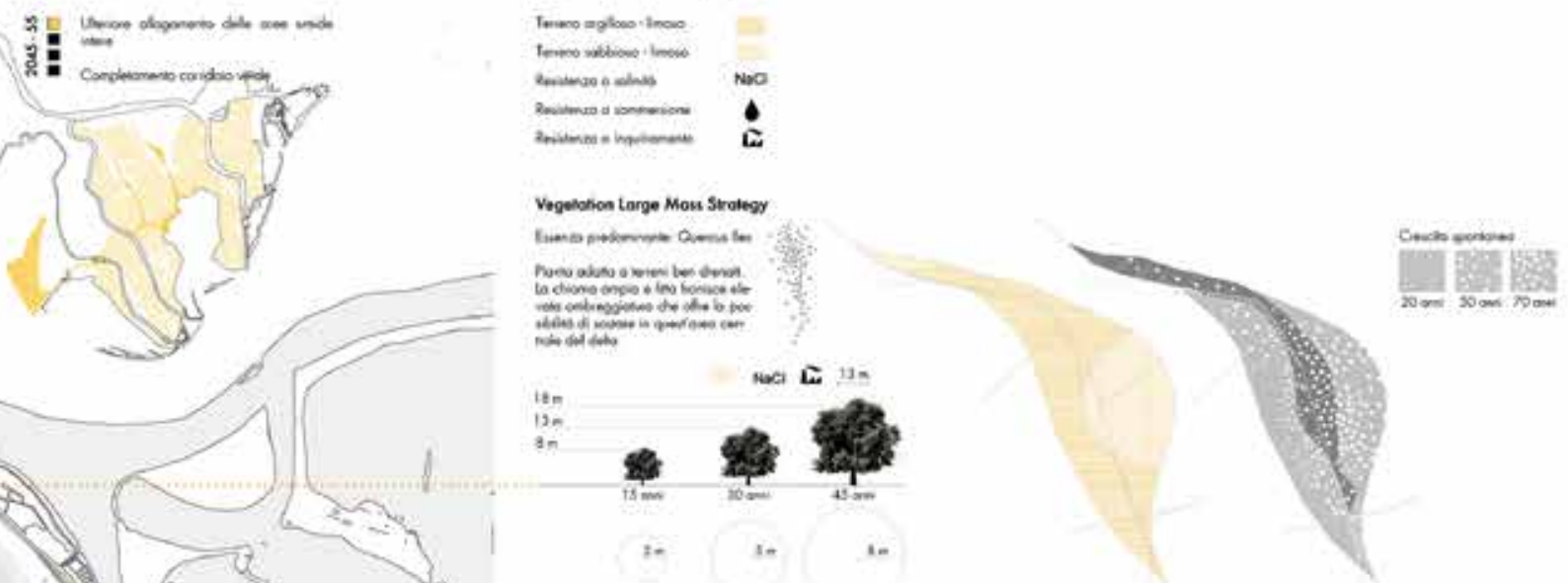

Sirip Gietnery Strenegr
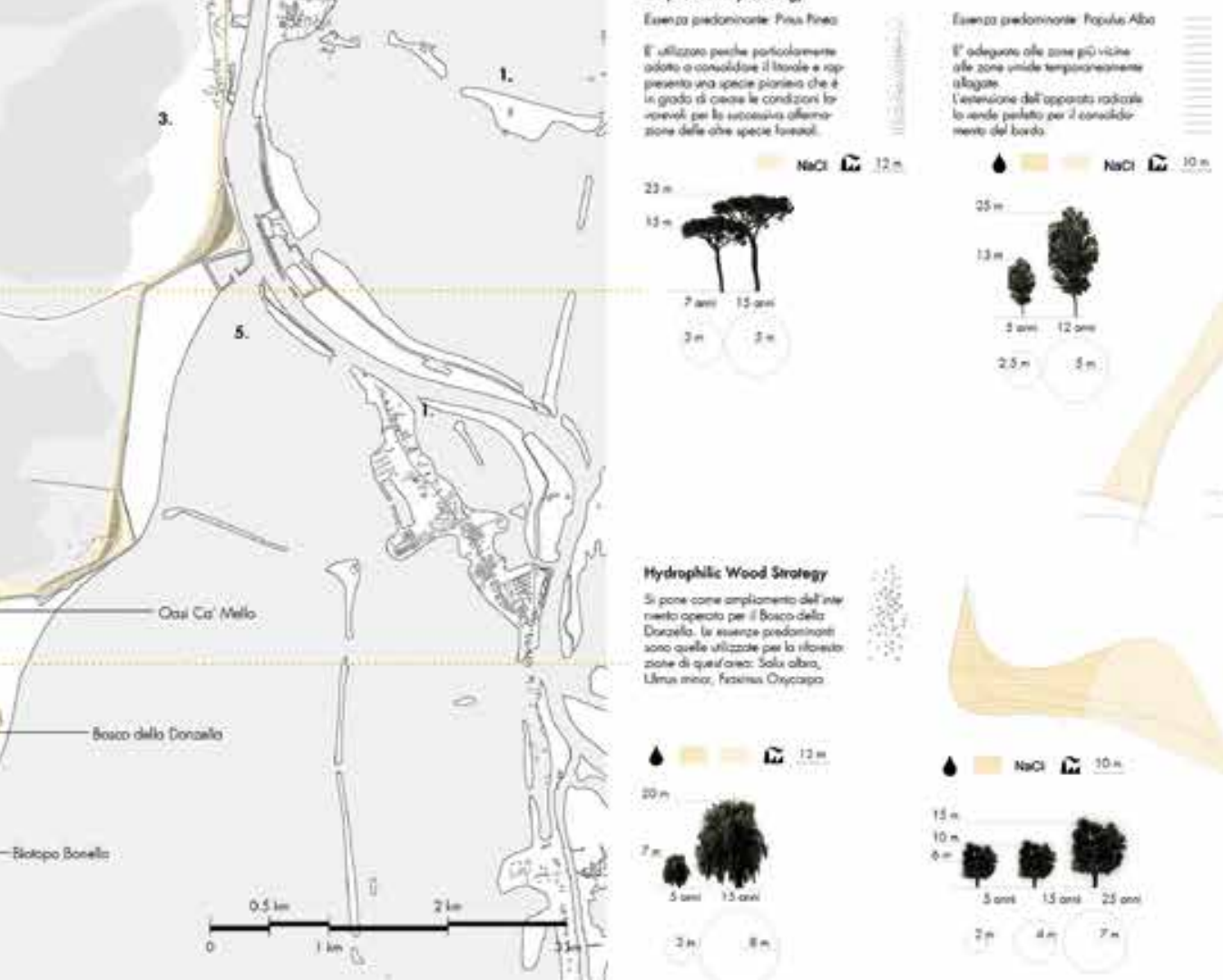

In 30
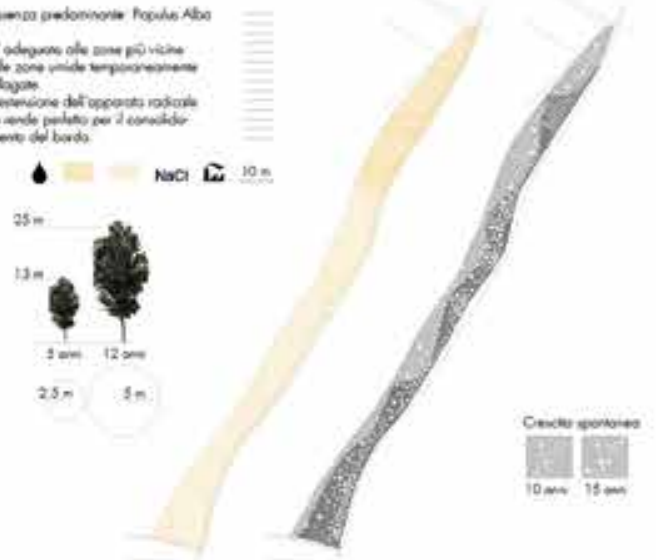

Mydrophlis Wood Sinclesy
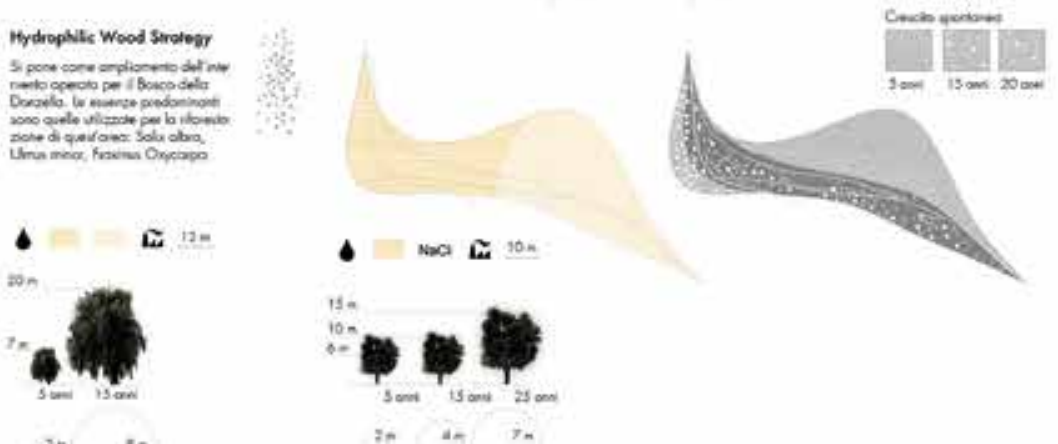

Fresh Woter Wollands
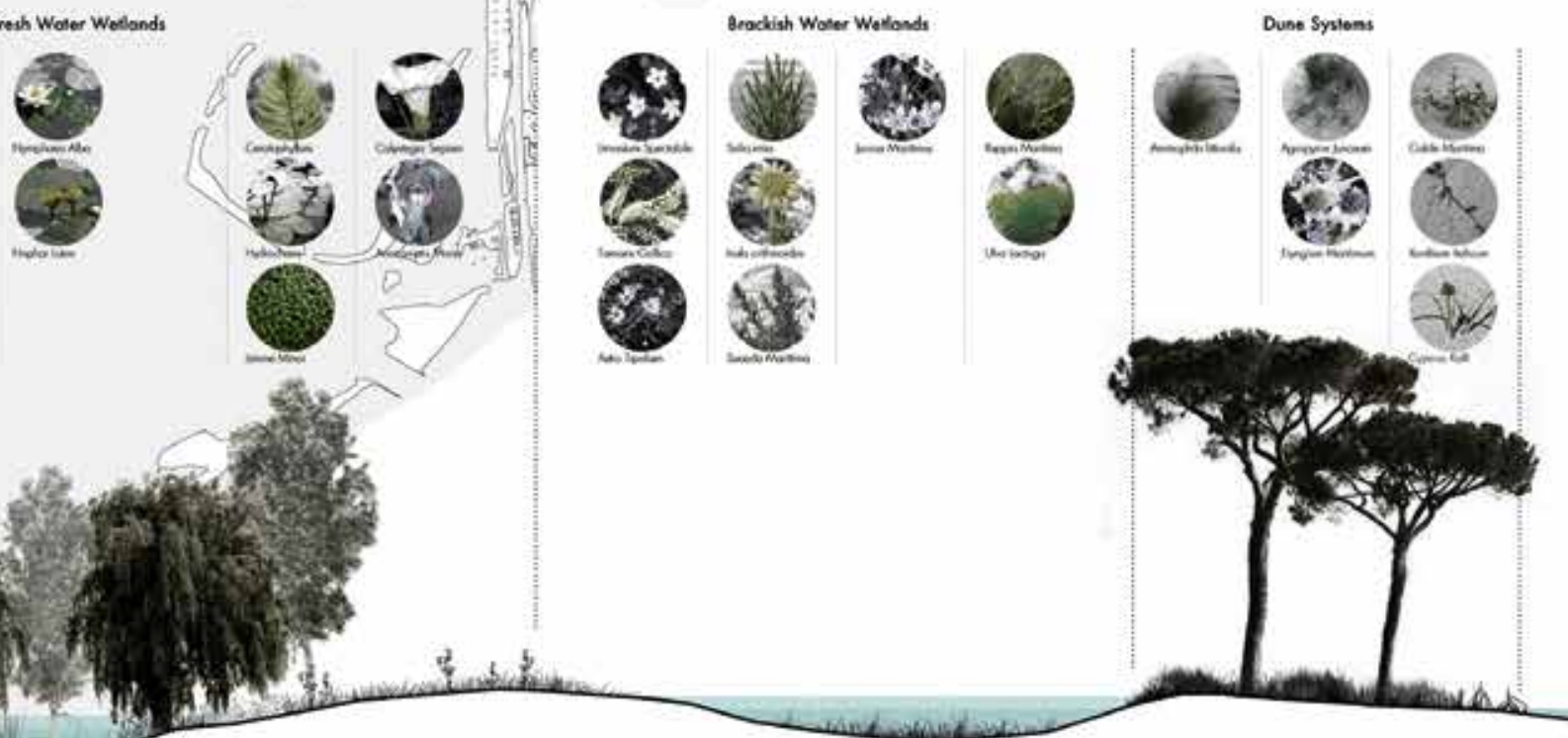

Figure 6. Some interventions concerning floods protection by wetlands and vegetation planting to improve the resilience. 
Unlike the current setting of the deltaic zones, featured by a sharp distinction between different environments, the proposed scenario should improve the inter-connections of different habitats fostering fauna's adaptability to future climate change and extreme events.

\section{CONCLUSIONS}

The idea of Hyper-Natural Environments informing the research on the Selective Retreat Strategy for the Po Delta is an attempt to define a new conceptual framework for landscape planning policies. In fact, it also aims at generating a change of attitude in the diverse territorial institutions involved in the delta management.

The neologism "hyper-natural" describes environments generated by the strong interaction between human actions and "natural" processes. Within this framework, the opposition between natural and artificial no longer applies. Persisting in this opposition could lead to misunderstandings or paralysis. In the case-study of the Po Delta, the overcoming of such an antithesis allows to plan a progressive site re-organization of a landscape shaped over the centuries by the continuous interaction of natural phenomena and human intervention. Since the effort to "freeze" the environmental evolution is no longer sustainable, dynamic scenarios should be planned to manage a soft and resilient transition to future arrangements (Nicolin, 2014).

The recent declaration by UNESCO of the Po Delta as one of the 651 Biosphere Reserves of the world ratifies the importance of this region and presents a new challenge. According to the MAB Program (the "Man and the Biosphere Programme" launched in 1971 by UNESCO), the proclamation purpose is to recognise and promote a balanced relationship between human communities and ecosystems. It also promotes the creation of on-site infrastructures for scientific research, environmental training and education, as well as experimental hubs for spatial planning policies. The Selective Retreat Strategy proposal is aimed at supporting a sustainable delta development, by exploiting its intrinsic changeability. The strategy supports an effective adaption strategy to climate change, eustatic sea level rise, fast subsidence, reduced fluvial sediment input and socio-economic expectations.

Far from being a rigid and definite design, the proposal wants to give alternative standpoints from which to start rethinking the future of the Po Delta. In fact, since the political feasibility of such a proposal could seem to be still difficult to implement, the added value of the Selective Retreat Strategy consists in being potentially used as a term of comparison: with the actual more conservative policies, as well as with other less radical options. Within this framework, the Selective Retreat System can be considered as an "exploratory scenario" aimed at grounding the debate around the delta on a more prospective outlook. 


\section{References}

Bondesan, Marco, G. B. Castiglioni, C. Elmi, G. Gabbianelli, R. Marocco, P. A. Pirazzoli, "Coastal areas at risk from storm surges and sea level rise in Northeastern Italy." Journal of Coastal Research (Fall 1995): 1354-1379.

Correa, Ivan D., and Juan Luis Gonzalez. "Coastal erosion and village relocation: a Colombian case study." Ocean \& Coastal Management 43, no. 1 (2000): 51-64.

Ferrarini, Lucia. "Paesaggi anfibi. Una strategia di ritiro selettivo per l'area del Delta del Po." Master's thesis, University of Ferrara, 2015.

Égré, Dominique, and Pierre Senécal. "Social impact assessments of large dams throughout the world: lessons learned over two decades." Impact Assessment and Project Appraisal 21 , no. 3 (2003): 215-224.

Gottmann, Jean. "Verso una megalopoli della pianura padana?" In Megalopoli mediterranea, edited by Calogero Muscarà, 19-31. Milan: Franco Angeli, 1978.

Leonhardt, Günther, Taneha K. Bacchin, Michael Mair, Jonatan Zischg, Stina Ljung, Briony Rogers, Lena Goldkuhl, et al. "Relocating a city, challenges and opportunities for the transition of water infrastructure in Kiruna." Paper presented at the 10th International Urban Drainage Modelling Conference, Mont-Sainte-Anne, CDN, September 2015.

Nilsson, Bo. "Ideology, environment and forced relocation: Kiruna-a town on the move." European Urban and Regional Studies 17, no. 4 (October 2010): 433-442.

Overeem, Irina, and Robert G. Brakenridge, eds. Dynamics and vulnerability of delta systems. LOICZ International Project Office, GKSS Research Centre, Institute for Coastal Research, 2009.

Milan, Daniele, Lorenza Perini and Cristina Tognon. Centro di documentazione della riforma agraria del Delta del Po: catalogo della mostra. Ariano nel Polesine, Rovigo (It.): Ente Parco Regionale Veneto del Delta del Po, 2004.

Nicolin, Pierluigi, ed. "Geography in motion." Lotus 115 (2014). Milan: Editoriale Lotus srl, 2014.

Pagnoni, Gian Andrea, et al. "Il valore della naturalità e la gestione degli interventi nelle lagune del delta del Po." Quaderni di Ca' Vendramin 0 (October 2009): 56-103.

Simeoni, Umberto et al. "Domains of spit evolution in the Goro area, Po Delta, Italy." Geomorphology 86, no. 3 (May 2007): 332-348.

Syvitski, James P.M. "Deltas at risk." Sustainability Science 3, no. 1 (February 2008): 23-32.

Speller, Gerda M., Evanthia Lyons, and Clare Twigger-Ross. "A community in transition: the relationship between spatial change and identity processes." Social psychological review 4, no. 2 (2002): 39-58.

Tosi, Maria Chiara. Toward an Atlas of the European Delta Landscape. Trento (It.): List Lab, 2013.

Tosini, Lino, and Pietro Colombo. Sessant'anni di bonifica nel delta del Po. Padua (It.): Papergraf, 2009.

Turri, Eugenio. La megalopoli padana. Venice (It.): Marsilio, 2000. 


\section{Acknowledgments}

We thank Lucia Ferrarini, Andrea Pavanati and Vera Pilloni for their friendly support and valuable help provided to the understanding of the Po Delta geology and landscape through their thesis research work. We also thank Massimo Tondello for his advice concerning the retreat scenarios from the Po Delta plain.

\section{Credits}

Figures 1-6: graphic works and drawings by Lucia Ferrarini.

Roberto Di Giulio is an architect, PhD, Full Professor and Dean of the Department of Architecture at the University of Ferrara, where he teaches Construction Design. Member of the Focus Area Cultural Heritage of the European Construction Technology Platform. Within the Department of Architecture, he is responsible of the Building Maintenance Laboratory (LEM). His research covers a broad range of issues from studies of materials performances and building design methodologies to investigation of building process management, maintenance strategies and building condition assessment. E-mail: dgr@unife.it

Luca Emanueli is an architect, $\mathrm{PhD}$, and a Full Professor of Landscape Design and Infrastructure Planning, Department of Architecture at the University of Ferrara.

$\mathrm{He}$ is the Director of Sealine and Coordinator of projects and researches, general advisor on investigation, design and urban planning of coastal systems. He studies the impact of tourism on metropolitan and landscape contexts and his work aims to provide new methodologies, tools and strategies for their smart development. E-mail: mnllcu@unife.it

Gianni Lobosco is an architect, PhD, and an Adjunct Lecturer in Landscape and Territorial Infrastructures Planning at Department of Architecture, University of Ferrara. He works on the relationships between mass tourism phenomena and infrastructures focusing on urban reuse strategies, seaborne mobility systems, coastal networks, intermodal developments and typological updating of accommodation facilities and services.

E-mail: gianni.lobosco@unife.it

Emanuele Piaia is an architect, PhD and a member of the LEM (Laboratory of Built Environment, Maintenance and Management) at the University of Ferrara, Department of Architecture, where he teaches. He is member of the INSITER research team financing by the Horizon 2020 program. Since 2009, he holds a Research Fellowship in Architecture Technology conducting studies in the assessment and definition of strategies, techniques and methods to upgrade the built heritage. He is a full member of the SITdA, the Italian Society of Architectural Technology. E-mail: emanuele.piaia@unife.it

Marco Stefani is a geologist, PhD. He worked at the Oxford University (UK), the Johns Hopkins University of Baltimore (Baltimore, MD, USA), the Caribbean Marine Research Centre (Bahamas), and the I.F.P. (Rueil Malmaison, Paris), on Mesozoic and Quaternary stratigraphy and environmental reconstruction. Since 1994, he has been working at the University of Ferrara, in both the departments of Earth Sciences and Architecture. His research work has been focusing on Mesozoic and Quaternary stratigraphy and palaeoenvironmental reconstruction of Southern Alpine, Po Plain and Adriatic areas. E-mail: marco.stefani@unife.it 